This is a peer-reviewed, accepted author manuscript of the following research article: BraunholtzSpeight, T., McLachlan, C., Mander, S., Hannon, M., Hardy, J., Cairns, I., Sharmina, M., \& Manderson, E. (Accepted/In press). The long term future for community energy in Great Britain: a co-created vision of a thriving sector and steps towards realising it. Energy Research and Social Science.

\title{
The long term future for community energy in Great Britain: a co-created vision of a thriving sector and steps towards realising it
}

\section{Keywords}

Community energy, energy transition, local energy

\section{Introduction}

The 'three Ds' of decarbonisation, decentralisation and digitisation are highlighted in many future energy visions[1-6]. These visions focus on developments such as the rise of distributed renewable electricity generation, smart local electricity grids and new technologies for electrifying transport and heat. The digitisation and decentralisation in these futures also place energy 'consumers' - or simply 'people' - centre stage $[2,7]$. Together, these changes are often labelled as the "energy transition".

Community energy initiatives - which in Great Britain ${ }^{1}$ are taken to be mainly locally-based third sector ${ }^{2}$ groups working on renewable energy generation or energy efficiency ${ }^{3}$ - are among those that suggest a 'fourth $D$ ' of democratisation be added to these visions. Given their focus on renewables and place-based organisation, they would seem to have bright prospects in a decentralised, decarbonised, citizen-centred future [8]. However, in many countries policy support for smaller scale and citizen-led energy projects has fluctuated in recent years [9-12]. In Britain, rapid growth in the sector has stalled following major cuts in government policy support for small-scale renewables that made investment in new projects highly risky[13-15].

Some work has begun to address the immediate way forward for the sector [16-20]. This work focusses on changes in community energy business models that are driven by the 'push' of these policy challenges. However, there is less work which focuses on how the 'pull' of the transition to a

\footnotetext{
${ }^{1}$ We use the term 'Great Britain' rather than 'United Kingdom' as the latter term refers to England, Scotland, Wales and Northern Ireland, but the research that this paper is based on was not conducted in Northern Ireland. Several aspects of energy regulation are different in Northern Ireland.

${ }^{2}$ The term 'third sector' refers to charities, social enterprises, voluntary organisations and similar groups. It includes a diverse range of 'not for profit' organisations that are neither part of the public sector (the state) nor the private sector (commercial 'for profit' organisations). For further information see the Third Sector Research Centre https://www.birmingham.ac.uk/research/tsrc/about-us/index.aspx or the National Council for Voluntary Organisations https://data.ncvo.org.uk/profile/voluntary-sector-definition/

${ }^{3}$ A substantial literature discusses what the 'community' in 'community energy' means, whether in principle or practice: key contributions include Walker and Devine-Wright 2008, Walker 2011, Creamer et al 2018.
} 
This is a peer-reviewed, accepted author manuscript of the following research article: BraunholtzSpeight, T., McLachlan, C., Mander, S., Hannon, M., Hardy, J., Cairns, I., Sharmina, M., \& Manderson, E. (Accepted/In press). The long term future for community energy in Great Britain: a co-created vision of a thriving sector and steps towards realising it. Energy Research and Social Science.

more decentralised energy system could drive the diversification and expansion of the sector, and the longer term potential of community energy to contribute to the energy transition. To address this gap, in 2018-19 we ran a series of workshops with community energy practitioners and stakeholders across Great Britain to co-create a long term vision of what the community energy sector could look like around 2050 if it were to realise its full potential. We took 'long term' to be 2050, in line with the Future Energy Scenarios produced by National Grid for the UK[21] (this timescale is also used by several other prominent energy and climate change targets and scenarios [22-24]).

In this paper we ask, firstly: what would a long term vision of thriving community energy sector look like? Specifically, we use the concept of business models ${ }^{4}$ to explore: what energy activities might community energy be engaged in and what are the implications in terms of the organisation, structure and resourcing of the sector? Secondly, using a backcasting approach, we identify steps to realise this vision: what would need to change from the present day GB energy system to make this vision possible? And, who would need to make these changes?

The rest of the paper is structured as follows. We first discuss the existing literature on the future of community energy and highlight the gap which our research is designed to fill. We then explain the methodology that guided our research, and describe the process of the workshops and subsequent analysis.

In our results, we present a co-created vision of community energy as expanded and diversified compared to the present day. The vision shows local groups cooperating through a Confederation, and running up to five different future business models: in renewables, flexibility, energy efficiency, mobility and heat. We identify the importance of actions by government - both at national and local level - to realising this vision, in combination with the efforts of the community energy sector itself of course.

Reflecting on these results, we conclude that our research highlights the possibilities for change in the institutional and spatial character of community energy; the sector's pragmatic attitude to the technological aspects of the energy transition; and its focus on community energy's role in delivering social and environmental co-benefits ${ }^{5}$, in line with the concept of a "just transition" [25]. We

\footnotetext{
${ }^{4}$ In this paper, our interpretation of the term 'business model' follows the business model canvas (Osterwalder and Pigneur, 2010). More details on this definition of business model are given in the methods section.

${ }^{5}$ In the discourse around climate change mitigation, 'co-benefits' refers to social and environmental benefits arising from action designed to mitigate climate change, that are not directly connected to the benefits of
} 
This is a peer-reviewed, accepted author manuscript of the following research article: BraunholtzSpeight, T., McLachlan, C., Mander, S., Hannon, M., Hardy, J., Cairns, I., Sharmina, M., \& Manderson, E. (Accepted/In press). The long term future for community energy in Great Britain: a co-created vision of a thriving sector and steps towards realising it. Energy Research and Social Science. conclude by placing our research in international context, and giving an overview of our analysis' limitations and suggestions for further work.

\section{Context}

The existing literature on the future of community energy suggests that community and local energy holds a consistent appeal as part of the energy transition; but that it also faces many challenges. The literature examines some short term options for new business models for community energy to overcome some of these challenges $[16,17]$, and in some cases discusses aspects of relevant longer term shifts in energy system business models, particularly in the area of local electricity markets [20, $26,27]$. There is also some literature on future scenarios for community energy [28-30] which tends to focus on possibilities for renewable electricity generation. Our research adds to this literature by: looking to the long term and considering how community energy could play a significant role is across various aspects of the energy transition; considering all parts of the energy system, addressing the supply and demand of power, heat, and transport; and identifying what needs to change to make a variety of business models feasible for community energy organisations. We consider national energy policy and the policy and practice of a wide range of relevant actors at different spatial scales and from different economic sectors. Finally, we reflect on what the cocreated vision reveals about how the community energy sector itself thinks about the future.

Much of the more recent literature on alternative business models for community energy focusses on local electricity markets and the revenue side of business models. Some discuss means of stabilising or increasing generation revenues from different arrangements for retail supply under current UK regulations, to coupling generation with storage to access flexibility revenue streams [1618, 31]. Hall and Roelich [26] discuss a range of what they term "business model archetypes" 6 for local electricity supply, using this lens to set out a range of energy distribution and revenue arrangements ranging from conventional pay-per-kilowatt-hour ( $\mathrm{kWh}$ ) models to energy service company (ESCo) and peer-to-peer models. Others look for new sources of revenue entirely, suggesting more radical shifts in business models towards aggregating Demand Side Response [20, 32], owning and operating EV charging infrastructure [33], or providing a platform for peer-to-peer trading of microgeneration [27]. However, analysis indicates it is unlikely that demand-side business

mitigating climate change itself, e.g. improvements in short-term air quality arising from phasing out fossil fuels in transport for long-term climate change mitigation.

${ }^{6}$ While not providing a theoretical definition, these "business model archetypes" are a series of conceptual models (Massa et al 2017) showing various ways in which energy and payments might flow between actors engaged in the local supply of electricity. 
This is a peer-reviewed, accepted author manuscript of the following research article: BraunholtzSpeight, T., McLachlan, C., Mander, S., Hannon, M., Hardy, J., Cairns, I., Sharmina, M., \& Manderson, E. (Accepted/In press). The long term future for community energy in Great Britain: a co-created vision of a thriving sector and steps towards realising it. Energy Research and Social Science.

models will be economically viable on their own [20], and suggests that 'prosumer' business models in general will need to combine multiple revenue streams ('revenue stacking') to work financially [27].

Another theme in the literature is uncertainty over the structure and governance of future community energy projects. Several studies suggest that a "hybrid" approach to community leadership, [17] involving partnerships with public or commercial actors [10, 31] may be necessary to access resources, achieve economies of scale and maximise impact. Brown et al [27] note that prosumerism can fit several "governance narratives", which include community or municipal energy, but also centralised and decentralised market narratives. Some of these points echo in the visions and scenarios literature. For example, the "Thousand Flowers" decentralised electricity scenario from the Realising Transition Pathways project [26, 34, 35] involves municipal and community energy companies, but the project's other scenarios detail private sector and central state-driven transitions. The project did not forecast which of these "logics" would dominate. More recently, Judson et al [36] note that "while decentralisation and democratisation can work together, it is not possible to assume any inherent relationship". In this paper we are not attempting any prediction of what pathway the energy transition will take; but rather we have worked with stakeholders to cocreate a vision where the full potential of community energy is realised in shaping and delivery of the energy transition and identify which actors will be important in determining whether such a vision happens in practice.

\section{Methods: co-creating a vision and steps for realising it}

This paper reports on workshops whose purpose was to explore longer term transformational possibilities for community energy. As stated in the Introduction above, the workshops were convened to help answer these questions: what would a long term vision of thriving community energy sector look like? What energy activities might community energy be engaged in and what are the implications in terms of the organisation, structure and resourcing of the sector? And who would need to do what to realise this vision and make these activities possible?

Mindful of the desirability of research having impact on society and policy as well as within academia [37]), we sought to co-create a vision that could play a 'performative' role [38]: influencing the discourse around community energy with the aim of changing practice and policy. Co-creation was important, firstly, to ensure that our vision was informed by the knowledge and aspirations of stakeholders who were likely to be key actors in realising it. Secondly, we hoped that providing time 
This is a peer-reviewed, accepted author manuscript of the following research article: BraunholtzSpeight, T., McLachlan, C., Mander, S., Hannon, M., Hardy, J., Cairns, I., Sharmina, M., \& Manderson, E. (Accepted/In press). The long term future for community energy in Great Britain: a co-created vision of a thriving sector and steps towards realising it. Energy Research and Social Science.

to discuss the longer term future with a wide cross-section of stakeholders would be valuable for participants in itself: to some extent, "researching and producing new social realities in the energy system, all at the same time"[39].

In taking this approach, we adopted a backcasting methodology. This is an approach commonly used for exploratory visioning exercises, particularly when these are orientated towards understanding how a desired transformation could be achieved over a long timescale [40-43]. The starting point for the backcasting was a positive vision of the future, co-created with stakeholders. This vision included two components: a wider energy system context, and outlines of business models that the community energy sector might operate in the longer term. They then worked backwards to outline the actors and changes needed to realise the vision[42], and demonstrate a "plausible link" [44] between the present day and the desired future. These steps are described in Section 3.1 and 3.2 respectively.

\subsection{Creating a desirable future vision for community energy}

The data and analysis presented in this paper are based on workshops held over 2018-19. Initial ideas for the community energy vision were gathered during a stakeholder workshop, held in Manchester in February 2018 as part of a series of stakeholder led engagement activities aimed at informing the local 5 Year Environment Plan (henceforth the "Scoping workshop": WS1 in Table 1). Following presentations on possible new directions for community energy from a range of actors in the sector, including financial and network innovations, facilitated group discussions scoped areas of future activity for community energy. The resulting data - in the form of worksheets, post-it notes and facilitator notes - were analysed to identify the areas of the energy system where stakeholders, and particularly community energy practitioners, wanted to focus for the long term.

Following this analysis, materials were developed for a series of workshops (henceforth the "Backcasting workshops") whose purpose was to further develop the vision, and use backcasting to set out pathways towards realising it. These materials had two components. Firstly, the analysis of the scoping workshop data was combined with a review of literature relevant to community energy futures. Then, to provide a structure to the vision, outlines of five business models that might form the basis of a future thriving community energy sector were developed. Each of the five business models focused on a different specific energy activity: generating renewable electricity, aggregating demand flexibility, insulating homes, charging electric vehicles, and running heat networks. However, rather than simply suggesting a list of energy activities, we used the concept of 'business model' as a "conceptual tool" [45] to ensure that, in thinking through what community energy might 
This is a peer-reviewed, accepted author manuscript of the following research article: BraunholtzSpeight, T., McLachlan, C., Mander, S., Hannon, M., Hardy, J., Cairns, I., Sharmina, M., \& Manderson, E. (Accepted/In press). The long term future for community energy in Great Britain: a co-created vision of a thriving sector and steps towards realising it. Energy Research and Social Science.

be in the future, our research considered all the "critical components" [45] necessary for an energy activity to be economically sustainable. The specific structure of these outline business models was based on the Business Model Canvas[46], which we selected because it provided a structured way of addressing the fundamental elements for building a business around these activities: what resources would be required, what goods and services might be offered to whom, what partnerships could be formed, and what the financial (cost and revenue) arrangements might look like. In addition, we included governance and ownership, finance, and social and community aspects elements in our outlines. While these are all elements that are not explicitly covered in the original Canvas[47], we made these additions to allow the expression of important factors for understanding how presentday community energy differentiated itself from the rest of the energy sector[14, 48], and therefore it was important to explore how they might change in the future. We did not attempt to quantify the financial aspects of these models, as we felt that it was not feasible to produce realistic estimates of costs and revenues for novel activities in 30 years' time. Indeed, long term visioning and backcasting approaches are generally not aimed at producing detailed blueprints of the future[41]. However, using the Canvas to cover all the key economic elements of business models enhanced the plausibility of our visioning exercise, especially given the context of a crisis in the economic viability of existing community energy models, and provided structure to discussions with research participants to ensure that they addressed these "critical components".

Secondly, we produced a summary of the National Grid's "Community Renewables" scenario, from their 2018 Future Energy Scenarios (FES) to frame our workshops in terms of both timescale, and scale of transformation from the present day energy system. Each year the National Grid ${ }^{7}$ produces a report presenting four Scenarios for the energy system in 2050, and thus we adopted 2050 as the date for the "long term" in our research. The Community Renewables was the most decentralised of the Scenarios produced by National Grid in their 2018 FES Report ${ }^{8}$, suggesting that by 2050 the majority of electricity will be generated at distribution or micro levels [21]. It also placed a heavy emphasis on the electrification of heat and transport, and on the uptake of smart energy management technology by consumers. The 2018 FES focussed on the technical aspects of the energy system: the technologies used and their configuration, with scenarios varying along axes of

\footnotetext{
${ }^{7}$ The UK's electricity transmission system operator, a private sector company.

${ }^{8}$ The others were Two Degrees, Consumer Evolution, and Steady Progression.
} 
This is a peer-reviewed, accepted author manuscript of the following research article: BraunholtzSpeight, T., McLachlan, C., Mander, S., Hannon, M., Hardy, J., Cairns, I., Sharmina, M., \& Manderson, E. (Accepted/In press). The long term future for community energy in Great Britain: a co-created vision of a thriving sector and steps towards realising it. Energy Research and Social Science.

decentralisation and decarbonisation; none of the four scenarios deal explicitly with questions of social or business organisation of any aspect of the system [21]. ${ }^{9}$

This framing allowed us to give a sense of the scale of decentralisation and decarbonisation being considered as a plausible future by a significant actor in the UK energy system, and acted as a prompt to discuss and articulate the role that community ownership and engagement could play in national level ambitions for the energy transition. In short, it was a tool to encourage backcasting workshop participants to 'think big', and avoid being limited by the focus on "the problematic present" [42] which (as we noted above) dominates the existing literature on community energy futures. We emphasised this to workshop participants and found that, while they accepted the Community Renewables scenario as a useful general framing of the energy transition, discussions were by no means bound by it.

\subsection{Vision and Backcasting workshops}

Over the winter of 2018-19, a Backcasting workshop was held in the capital of each of three of the Great Britain's (GB) three nations (i.e. Edinburgh, Scotland; London, England; Cardiff, Wales). Locations were chosen to maximise accessibility and participation from 40 stakeholders across GB, and to capture the different contexts for community energy within the devolved administrations. Participants were invited on their basis of their expertise and experience within the community energy sector, and their interest in, and enthusiasm for, its long-term future. We sought to overcome potential biases in recruitment[39] through inviting people with experience of different technologies and from different regions, and through offering expenses and a nominal payment to invitees from smaller third sector organisations unable to finance their own participation. Around half of the participants were community energy practitioners. The remainder were drawn from central and local government (public sector), the energy and finance private sector (including financial and legal firms that specialise in community energy), other third sector organisations (including charities specialising in energy, sustainability and community development), and other policy and research bodies with expertise in community energy (details of numbers at each workshop can be found in Table 1).

\footnotetext{
${ }^{9}$ Note that the most recent (2020) Future Energy Scenarios document explicitly notes the importance of societal transformation, while on the other hand "Community Renewables" has been replaced by "Consumer Transformation" in the scenario titles.
} 
This is a peer-reviewed, accepted author manuscript of the following research article: BraunholtzSpeight, T., McLachlan, C., Mander, S., Hannon, M., Hardy, J., Cairns, I., Sharmina, M., \& Manderson, E. (Accepted/In press). The long term future for community energy in Great Britain: a co-created vision of a thriving sector and steps towards realising it. Energy Research and Social Science.

Table 1 Workshop participation

\begin{tabular}{|c|c|c|c|c|c|c|c|c|}
\hline \multirow[t]{2}{*}{ Location } & \multirow[t]{2}{*}{ Date } & \multirow[t]{2}{*}{ Duration } & \multirow[t]{2}{*}{ Total } & \multicolumn{4}{|l|}{ Of which } & \multirow[b]{2}{*}{$\begin{array}{l}\text { Research / } \\
\text { consultancy }\end{array}$} \\
\hline & & & & $\begin{array}{l}\text { Community } \\
\text { energy }\end{array}$ & $\begin{array}{l}\text { Private } \\
\text { sector }\end{array}$ & $\begin{array}{l}\text { Public } \\
\text { sector }\end{array}$ & $\begin{array}{l}\text { Other } \\
\text { third } \\
\text { sector }\end{array}$ & \\
\hline \multicolumn{9}{|c|}{ Scoping Vision workshop } \\
\hline $\begin{array}{l}\text { Manchester } \\
\text { (WS1) }\end{array}$ & $\begin{array}{l}\text { February } \\
2018\end{array}$ & 1 day & 49 & 12 & 16 & 10 & 8 & 3 \\
\hline \multicolumn{9}{|c|}{ Refining Vision and Backcasting workshops } \\
\hline $\begin{array}{l}\text { Edinburgh } \\
\text { (WS2) }\end{array}$ & $\begin{array}{l}\text { December } \\
2018\end{array}$ & 1 day & 11 & 6 & 0 & 1 & 2 & 2 \\
\hline $\begin{array}{l}\text { London } \\
\text { (WS3) }\end{array}$ & $\begin{array}{l}\text { January } \\
2019\end{array}$ & 1 day & 21 & 10 & 4 & 2 & 1 & 4 \\
\hline $\begin{array}{l}\text { Cardiff } \\
\text { (WS4) }\end{array}$ & $\begin{array}{l}\text { January } \\
2019\end{array}$ & 1 day & 11 & 6 & 1 & 1 & 1 & 2 \\
\hline
\end{tabular}

Prior to the Backcasting Workshops, all participants were sent a briefing pack containing the outlines of the five community energy business models (see Appendix for the original outlines); and a twopage summary of the National Grid's "Community Renewables" Future Energy Scenario, to provide a sense of the scale of long term transformation of the energy system we were interested in exploring. The outlines were developed drawing on the results of the analysis of the Scoping Workshop data, and a review of the literature on community energy futures. They were kept brief, focussing on resources needed to perform the activity, possible customer types, and the scale at which it might work.

Workshops began with a plenary session that invited general feedback on the business model outlines. Then break-out groups, of between four and eight participants, developed in more detail the governance, finance and specifically 'community' aspects of each of the business models outlined within the visions. In the afternoon, self-selected group of participants outlined pathways to realise those visions, writing what they thought needed to happen on post-its and placing these on large sheets marked from 'now' to '2050'; and then discussing what they had written. As noted above, however, we were keen to not restrict discussion, so participants were welcome to suggest their own potential business models, and/or to reject National Grid's "Community Renewables" scenario as a framing of the low carbon transition. As participants chose which business models they wanted to produce pathways for, and one model did not have a pathway produced (see section 5 for more detail). 
This is a peer-reviewed, accepted author manuscript of the following research article: BraunholtzSpeight, T., McLachlan, C., Mander, S., Hannon, M., Hardy, J., Cairns, I., Sharmina, M., \& Manderson, E. (Accepted/In press). The long term future for community energy in Great Britain: a co-created vision of a thriving sector and steps towards realising it. Energy Research and Social Science.

\subsection{Analysis of data}

Data from the initial Scoping workshop was captured in the form of worksheets completed by groups of up to eight participants, post-its, and facilitator notes. These data were analysedto identify common themes and novel ideas about the future of the sector: whether those were concerned with particular energy activities, or other aspects of business models (e.g. sources of finance).

Data from the three Backcasting workshops was captured in the form of post-its, sheets completed by the break-out groups and audio recordings of all discussions during workshop sessions (one recorder on every table), which were transcribed. The written data from the day were digitised, and documents created comparing participants' comments on the structure, finance and community elements of the outline business models. All the steps and changes recorded on the "pathways" sheets were digitised, and then coded into themes and analysed manually. As there was a manageable volume of entirely qualitative data, this was felt the best way to approach the analysis. Extensive reference was made to the transcripts of workshop discussions, both to identify additional points, and to add depth and clarification to written notes.

The data captured in our workshops shows the opinions, hopes and concerns of a collection of experienced community energy practitioners, and stakeholders from the public and private sectors. Analysis of this data can help reveal the range of views within the sector on the wider energy system today, and how the sector approaches the future.

\section{Results: a long-term vision for community energy}

This section presents the long-term vision resulting from our research. The next section (5) the actors and actions identified through the backcasting process as key to overcoming barriers to realising this vision.

Our participants outlined a vision where community energy was widespread across heat, mobility and electricity. This vision has two parts to it: a wider energy system context within which community energy would operate and, a set of business model outlines that describe what community energy organisations would be doing in the long-term future.

While we originally set the 'long term' at 2050, in line with the Future Energy Scenarios, in practice, this conceptualisation of the 'long term' was modified and brought forward by some years during the course of the workshops. Participants felt that focussing on 2050 ignored the urgency of the 
This is a peer-reviewed, accepted author manuscript of the following research article: BraunholtzSpeight, T., McLachlan, C., Mander, S., Hannon, M., Hardy, J., Cairns, I., Sharmina, M., \& Manderson, E. (Accepted/In press). The long term future for community energy in Great Britain: a co-created vision of a thriving sector and steps towards realising it. Energy Research and Social Science.

issues they were seeking to address. This quotation illustrates a position that we found to be widely held, if not always so forthrightly expressed:

"I want it all and I want it now! [Laughter from other participants.] If we're thinking 2050 then Christ, if we haven't got this sorted by then, there will be trouble."

Participant, Cardiff workshop

Therefore, based on the results of the Backcasting workshops, timescale terms used in this paper should be understood as follows: short term refers to the next two to three years (2019-2022); medium term refers to from then up until around 2030; long term refers to between 2030 and 2050

\subsection{The long-term context}

Community energy organisations would be operating in an energy system structure, and energy culture, quite different from the present day. Today the GB energy system remains largely centralised[49], with the majority of supply, transmission and distribution of electricity and gas (for heating) in the hands of a small number of private companies[50]. Energy is traded in UK-wide markets, with suppliers also obliged to accept customers from anywhere in the country. While progress has been made in decarbonising the electricity sector in recent decades, there has been little progress in decarbonising heat, or in addressing the energy inefficiency of housing[51].

In contrast, in the co-created vision, local energy markets - where energy is traded at a sub-national level, encouraging local use of generation - would be well established across the whole UK. Buying 'local' energy would be a normal thing for a household to do. Citizens would be more 'energy literate', more engaged in how much energy they use, and where they get it from, than today. Decentralised balancing, through demand-side response (DSR) balancing local consumption with local generation of energy, would make citizens key players in energy system operation. Transport would be decarbonised, and there would be more use of public transport than today. And not only would new buildings be very energy efficient, but the 'retrofit' of existing housing stock would have been accomplished, and fuel poor households living in cold damp dwellings would be a thing of the past.

Alongside the community organisations that our participants focussed on, many saw the public sector play a greater role than in today's energy system. Local authorities would be active players in energy markets, enabled by national government promoting openness and equality in those markets through funding and regulation. While none envisaged wholesale nationalisation, some suggested that elements of the energy system, e.g. the transmission and distribution network, would be in 
This is a peer-reviewed, accepted author manuscript of the following research article: BraunholtzSpeight, T., McLachlan, C., Mander, S., Hannon, M., Hardy, J., Cairns, I., Sharmina, M., \& Manderson, E. (Accepted/In press). The long term future for community energy in Great Britain: a co-created vision of a thriving sector and steps towards realising it. Energy Research and Social Science.

public ownership. The wider public policy framework would support decarbonisation, with climate change and wider environmental considerations central to decision-making. The economy as a whole would be more localised and mutualised.

These changes were seen as necessary for community energy to achieve its maximum potential in terms of scale of operation and engagement across the energy system, but would require major policy and political change, beyond the energy sector.

\subsection{The long-term future business models}

Within the changed energy system just outlined, there would be many opportunities for new citizenfocussed and local energy business models. Driven by the opportunities presented by new revenue streams at local scale - e.g. in local energy sales, local grid balancing, or transport - and by the desire to maximise the social and environmental benefits flowing from this new energy system, community energy would diversify. As well as renewable generation, community organisations would work with citizens and energy customers to provide energy demand flexibility, or help them save energy and money through more efficient use of energy. Community energy groups would become more active in the transport and heat sectors, although participants did not see these becoming as important to community energy as electricity generation, flexibility and efficiency. A new institution, a Community Energy Confederation, was also proposed, to act as a broker to ensure local organisations operating one (or more) of the future business models get the best deals in regional or national markets. The specific business models envisaged for working in these areas are outlined below, with further detail given in Tables 2 and 3:

Community Energy Confederation: an organisation whose members would be local community energy groups, trading both renewable generation and demand-side flexibility in regional or national markets on its members' behalf. Possibly also facilitating cooperation among local groups running the other future business models listed below, particularly Low Carbon Mobility (given the relevance of cooperation over a wider geographical area for transport). The reasoning and debates around the role and structure of the Confederation are given in more detail in 4.3 below.

Community Renewable Electricity Companies: generate electricity; sell it to local customers; and sell any surplus nationally as part of a wider-scale Community Energy Confederation (see below). Community Renewable Electricity Companies would be widespread across the UK.

Local Energy Aggregators: aggregate their members' capacity to shift their electricity demand to different times of day, and trade in flexibility markets on their behalf. Again, these markets might be 
This is a peer-reviewed, accepted author manuscript of the following research article: BraunholtzSpeight, T., McLachlan, C., Mander, S., Hannon, M., Hardy, J., Cairns, I., Sharmina, M., \& Manderson, E. (Accepted/In press). The long term future for community energy in Great Britain: a co-created vision of a thriving sector and steps towards realising it. Energy Research and Social Science.

local, or trading might be on a larger scale and organised through the Community Energy

Confederation (see below). They would likely also operate online platforms which individuals could use (for a fee) to trade energy independently.

Energy Saving Services: locally-rooted and controlled organisations continuing to offer energy advice, and to work with local trades cooperatives to install and maintain the latest energy-saving and energy management technology, in homes and workplaces; financing this through "pay as you save" revenue from customers paying in instalments over time (Cairns and Hannon et al 2020Bhesco) or instead grant-funded (see section 5.1).

Low Carbon Mobility: community energy groups running low carbon transport schemes, based on a 'multi-mode mobility' model. A single pass - a card and/or a smartphone app - would give members access to several low carbon transport options: EV charging, but also EV hire, electric bike hire, or electric bus and tram travel.

Note that this business model divided workshop participants. The initial outline we presented (see Appendix) was focussed on providing EV charging only. Many participants felt that even this was not feasible, as private companies are already too well established in the electric transport sector for community organisations to compete with. They therefore saw this sector only in terms of people using EV batteries to provide local flexibility aggregation. Conversely, other participants felt that EV charging alone was much too unambitious, and developed the more holistic mobility-focussed business model described above and in Table 3. Steps needed to make this more ambitious business model a reality are outlined in Section 5 below.

District Heat Networks: the complexity of developing heat networks meant that these were judged likely to remain a relatively small part of the overall community energy sector. Nevertheless, an expansion of community activity in heat networks was envisaged. One possibility was for community organisations to partner with larger bodies (perhaps local authorities) that would provide an 'anchor load'. While this would mean loss of overall control, and therefore revenue, it would also reduce workload and risk; and one suggestion was that community groups might be paid by the larger body for their community engagement work. This presents the reputational risk, however, of becoming the public face of a project over which the community organisation has little control.

Alternatively, working at a smaller scale, shared loop heat pumps connecting small numbers of houses were proposed as a potential community heat niche, and a practical way to provide 
This is a peer-reviewed, accepted author manuscript of the following research article: BraunholtzSpeight, T., McLachlan, C., Mander, S., Hannon, M., Hardy, J., Cairns, I., Sharmina, M., \& Manderson, E. (Accepted/In press). The long term future for community energy in Great Britain: a co-created vision of a thriving sector and steps towards realising it. Energy Research and Social Science.

collective low carbon heat to some of the over 2 million UK households off the gas grid in the UK [52]. 
This is a peer-reviewed, accepted author manuscript of the following research article: BraunholtzSpeight, T., McLachlan, C., Mander, S., Hannon, M., Hardy, J., Cairns, I., Sharmina, M., \& Manderson, E. (Accepted/In press). The long term future for community energy in Great Britain: a co-created vision of a thriving sector and steps towards realising it. Energy Research and Social Science.

\section{Table 2 Community Energy Confederation - Business Model Outline}

\begin{tabular}{|l|l|}
\hline Element & Community Energy Federation \\
\hline Key activities & $\begin{array}{l}\text { - Trading renewable generation and flexible demand-side response } \\
\text { - Providing finance and support to facilitate member projects } \\
\text { - Possibly directly investing in large-scale renewable electricity generation }\end{array}$ \\
\hline Revenue and customers & $\begin{array}{l}\text { - Distribution or Transmission System Operators } \\
\text { - Energy utilities }\end{array}$ \\
\hline Resources & $\begin{array}{l}\text { - Network of generators and electricity consumers } \\
\text { - Renewable electricity and flexibility capacity }\end{array}$ \\
\hline Cost profile & - Low upfront and running costs \\
\hline Finance & $\begin{array}{l}\text { - Community shares } \\
\text { - Crowdfunded bonds } \\
\text { - Membership fees } \\
\text { - Long term investments from pension funds or 'ethical' financial institutions }\end{array}$ \\
\hline Ownership and structure & $\begin{array}{l}\text { - Cooperative of cooperatives or other community groups - local projects } \\
\text { controlling central hub }\end{array}$ \\
\hline Geography and scale & $\begin{array}{l}\text { - Existing projects join as their current PPAs expire } \\
\text { - Central hub - all in-house or outsourced? }\end{array}$ \\
\hline $\begin{array}{l}\text { Other business models it } \\
\text { facilitates }\end{array}$ & $\begin{array}{l}\text { - Particularly relevant to Community Renewable Electricity Companies, Local } \\
\text { Energy Aggregators, Low Carbon Mobility }\end{array}$ \\
\hline Key community aspects & $\begin{array}{l}\text { - Membership also open to groups involved only in Energy Saving Services and } \\
\text { District Heat Networks } \\
\text { - Provides finance, technical and legal support in addition to marketing of } \\
\text { energy services }\end{array}$ \\
\hline
\end{tabular}


This is a peer-reviewed, accepted author manuscript of the following research article: Braunholtz-Speight, T., McLachlan, C., Mander, S., Hannon, M., Hardy, J., Cairns, I., Sharmina, M., \& Manderson, E. (Accepted/In press). The long term future for community energy in Great Britain: a co-created vision of a thriving sector and steps towards realising it. Energy Research and Social Science.

\section{Table 3 Potential future community energy business models}

\begin{tabular}{|c|c|c|c|c|c|}
\hline Element & $\begin{array}{l}\text { Community Renewable } \\
\text { Electricity Company }\end{array}$ & Local Energy Aggregator & Energy Saving Services & Low Carbon Mobility & District Heat Network \\
\hline Energy activity & Generating electricity & $\begin{array}{l}\text { Trading microgeneration and } \\
\text { demand flexibility }\end{array}$ & $\begin{array}{l}\text { Energy efficient renovations } \\
\text { and installations }\end{array}$ & $\begin{array}{l}\text { Mixed mobility services } \\
\text { - EV clubs, buses }\end{array}$ & $\begin{array}{l}\text { Generating renewable heat and } \\
\text { supplying end users }\end{array}$ \\
\hline $\begin{array}{l}\text { Revenue and } \\
\text { customers }\end{array}$ & $\begin{array}{l}\text { - Sale of electricity to } \\
\text { individual and } \\
\text { organisational customers in } \\
\text { local energy market } \\
\text { - Sale of electricity to } \\
\text { national energy retailer via } \\
\text { PPA }\end{array}$ & $\begin{array}{l}\text { - Flex contracts with local } \\
\text { system operators } \\
\text { - Platform fees for } \\
\text { independent energy traders }\end{array}$ & $\begin{array}{l}\text { - Fees for installations } \\
\text { and works - "Pay as you } \\
\text { Save" basis } \\
\text { - Individuals or organisations } \\
\text { - Energy advice given for free } \\
\text { - social benefit }\end{array}$ & $\begin{array}{l}\text { - Membership / app } \\
\text { subscriptions - potential for } \\
\text { concessionary rates } \\
\text { - Public EV charging fees } \\
\text { - Individuals, potentially } \\
\text { corporate customers }\end{array}$ & $\begin{array}{l}\text { - Heat sold to domestic and } \\
\text { organisational customers } \\
\text { - Potentially Heat As A Service } \\
\text { to incentivise network } \\
\text { efficiency }\end{array}$ \\
\hline Resources & $\begin{array}{l}\text { Renewable electricity } \\
\text { generators }\end{array}$ & $\begin{array}{l}\text { - Open standard smart } \\
\text { meters } \\
\text { - Monitoring and trading } \\
\text { software } \\
\text { - IT skills }\end{array}$ & $\begin{array}{l}\text { - Appliances, materials and } \\
\text { equipment } \\
\text { - Low carbon construction } \\
\text { skills } \\
\text { - Customer relations }\end{array}$ & $\begin{array}{l}\text { - Vehicles, charging } \\
\text { infrastructure, software } \\
\text { - Drivers, customer relations }\end{array}$ & $\begin{array}{l}\text { - Renewable heat generators } \\
\text { and supply infrastructure } \\
\text { - Fuel/feedstock } \\
\text { - Heat expertise } \\
\text { - Customer relations }\end{array}$ \\
\hline Cost profile & $\begin{array}{l}\text { - High upfront costs, lower } \\
\text { running costs }\end{array}$ & $\begin{array}{l}\text { - Relatively low upfront and } \\
\text { running costs. }\end{array}$ & $\begin{array}{l}\text { - Undulating - ongoing } \\
\text { labour costs, purchases of } \\
\text { equipment and materials }\end{array}$ & $\begin{array}{l}\text { - Potentially high upfront and } \\
\text { running costs (leasing tech } \\
\text { may lower upfront costs) }\end{array}$ & $\begin{array}{l}\text { High upfront costs, medium } \\
\text { running costs }\end{array}$ \\
\hline Finance & $\begin{array}{l}\text { - Local projects: mix of bonds } \\
\text { (for scale) and community } \\
\text { shares (to keep equity } \\
\text { local) } \\
\text { - Larger projects: as local, } \\
\text { consider also more } \\
\text { mainstream finance e.g. } \\
\text { pension funds? }\end{array}$ & $\begin{array}{l}\text { - Community shares and/ or } \\
\text { membership fees } \\
\text { - Integrate with Renewables } \\
\text { Federation finance? }\end{array}$ & $\begin{array}{l}\text { - Long-term grant funding for } \\
\text { hardest-to-retrofit or fuel } \\
\text { poor households }\end{array}$ & - Community shares and bonds & $\begin{array}{l}\text { - Smaller projects: community } \\
\text { shares and bonds - maybe } \\
\text { refinancing construction loans } \\
\text { - Public sector loans and grant } \\
\text { funding } \\
\text { - Cheap capital via larger } \\
\text { partners }\end{array}$ \\
\hline $\begin{array}{l}\text { Ownership and } \\
\text { structure }\end{array}$ & $\begin{array}{l}\text { - Structures to fit local } \\
\text { context - standalone } \\
\text { coops, or community-led } \\
\text { partnerships, both possible } \\
\text { - If local energy retailer then } \\
\text { could become consumer } \\
\text { coop? }\end{array}$ & $\begin{array}{l}\text { - Local groups with } \\
\text { households and businesses } \\
\text { as members } \\
\text { - Wider scale Confederation } \\
\text { dealing with network } \\
\text { operators }\end{array}$ & $\begin{array}{l}\text { - Local cooperatives - of } \\
\text { consumers, or of trades } \\
\text { - Or other community } \\
\text { company structures? }\end{array}$ & $\begin{array}{l}\text { - Local cooperatives } \\
\text { - Network of local } \\
\text { cooperatives facilitating } \\
\text { inter-operability - again } \\
\text { could be the Confederation. } \\
\text { - RESCoop (Europe) provides } \\
\text { model }\end{array}$ & $\begin{array}{l}\text { - Small standalone } \\
\text { cooperatives or other } \\
\text { community companies } \\
\text { - Partnerships with larger } \\
\text { organisations providing } \\
\text { 'anchor load' }\end{array}$ \\
\hline
\end{tabular}


This is a peer-reviewed, accepted author manuscript of the following research article: Braunholtz-Speight, T., McLachlan, C., Mander, S., Hannon, M., Hardy, J., Cairns, I., Sharmina, M., \& Manderson, E. (Accepted/In press). The long term future for community energy in Great Britain: a co-created vision of a thriving sector and steps towards realising it. Energy Research and Social Science.

\begin{tabular}{|c|c|c|c|c|c|}
\hline $\begin{array}{l}\text { Geography / } \\
\text { scale }\end{array}$ & $\begin{array}{l}\text { - Local projects selling to } \\
\text { local customers } \\
\text { - network across the UK } \\
\text { (through the Federation) }\end{array}$ & $\begin{array}{l}\text { - Local or regional? scale for } \\
\text { economic viability and } \\
\text { market rules not yet clear }\end{array}$ & $\begin{array}{l}\text { - Local - maximising local } \\
\text { social networks and } \\
\text { reputation }\end{array}$ & $\begin{array}{l}\text { - Local to regional. May be } \\
\text { different in rural and urban } \\
\text { areas }\end{array}$ & $\begin{array}{l}\text { - Local - from micro to city } \\
\text { wide }\end{array}$ \\
\hline $\begin{array}{l}\text { Member of } \\
\text { Confederation? }\end{array}$ & Yes & Yes & Possibly & Yes & Possibly \\
\hline $\begin{array}{l}\text { Key community } \\
\text { aspects }\end{array}$ & $\begin{array}{l}\text { Spend and revenues used to } \\
\text { promote inclusive local } \\
\text { economic and social } \\
\text { development } \\
\text { Psychological and cultural } \\
\text { benefits from communities } \\
\text { taking control }\end{array}$ & $\begin{array}{l}\text { Higher participation in flex } \\
\text { and DSR due to: } \\
\text { - Trust - essential to get } \\
\text { people to participate in } \\
\text { smart energy systems } \\
\text { - Fair deal for all - } \\
\text { overcoming digital divide } \\
\text { and ensuring all get share } \\
\text { of revenues from value } \\
\text { they create }\end{array}$ & $\begin{array}{l}\text { Better coverage and } \\
\text { outcomes through } \\
\text { - Accountability and trust } \\
\text { through long term local } \\
\text { presence } \\
\text { - Knowledge of local issues } \\
\text { and housing stock }\end{array}$ & $\begin{array}{l}\text { Local economic and social } \\
\text { benefit - providing transport to } \\
\text { those in need, local } \\
\text { procurement and employment }\end{array}$ & $\begin{array}{l}\text { Better value for members } \\
\text { Accountability and trust through } \\
\text { long term local presence - and } \\
\text { through cooperative } \\
\text { governance structure? }\end{array}$ \\
\hline Drivers of uptake & $\begin{array}{l}\text { - Increased demand for } \\
\text { renewable electricity } \\
\text { generation for transport } \\
\text { and heat } \\
\text { - Existing sector expertise in } \\
\text { renewables } \\
\end{array}$ & $\begin{array}{l}\text { - Smart technology and } \\
\text { energy decentralisation } \\
\text { increasing importance of } \\
\text { customer demand } \\
\text { management to energy } \\
\text { system operation } \\
\end{array}$ & $\begin{array}{l}\text { - Health and decarbonisation } \\
\text { imperatives for better } \\
\text { housing } \\
\text { - Huge stock of energy- } \\
\text { inefficient buildings to } \\
\text { upgrade }\end{array}$ & $\begin{array}{l}\text { - Electric transport } \\
\text { opportunity: } \\
\text { - air quality } \\
\text { - decarbonisation policy } \\
\text { - technology maturing }\end{array}$ & $\begin{array}{l}\text { Decarbonisation policy, } \\
\text { technology proven, cost } \\
\text { saving potential }\end{array}$ \\
\hline Barriers to uptake & $\begin{array}{l}\text { - Difficulty of accessing } \\
\text { finance esp. for larger scale } \\
\text { projects } \\
\text { - Revenue uncertainty post- } \\
\text { FITs and RO }\end{array}$ & $\begin{array}{l}\text { - Llow level of revenue; } \\
\text { - Uuncertainties over viable } \\
\text { scale } \\
\text { - Regulations currently limit } \\
\text { activity }\end{array}$ & $\begin{array}{l}\text { - Financial costs to building } \\
\text { owners or residents; } \\
\text { - Disruption to residents; } \\
\text { - Scepticism of performance }\end{array}$ & $\begin{array}{l}\text { Electricity and mobility } \\
\text { dominated by large scale } \\
\text { incumbents } \\
\text { - Dominant technologies not } \\
\text { yet clear in all aspects }\end{array}$ & $\begin{array}{l}\text { - Capital cost } \\
\text { - Complexity of retrofit of heat } \\
\text { networks }\end{array}$ \\
\hline $\begin{array}{l}\text { Overcoming } \\
\text { barriers to uptake }\end{array}$ & $\begin{array}{l}\text { - Confederation to act as } \\
\text { financing broker and } \\
\text { project development } \\
\text { support } \\
\text { - Public sector purchase and } \\
\text { incentivise community } \\
\text { renewables } \\
\text { - Private sector provide } \\
\text { patient finance at scale }\end{array}$ & $\begin{array}{l}\text { - Integrate into } \\
\text { Confederation to improve } \\
\text { economies of scale } \\
\text { - Work with partners in local } \\
\text { government or third sector } \\
\text { to increase scale } \\
\text { - Regulate to facilitate small } \\
\text { actors' participation in } \\
\text { flexibility markets }\end{array}$ & $\begin{array}{l}\text { - Long term public funding } \\
\text { for energy retrofit } \\
\text { - Community approach } \\
\text { improves accountability, } \\
\text { standards and trust } \\
\text { - Work with partners in local } \\
\text { government or third sector } \\
\text { to increase scale }\end{array}$ & $\begin{array}{l}\text { - Leasing rather than buying } \\
\text { technologies } \\
\text { - Find niches e.g. rural } \\
\text { - Partner with organisations } \\
\text { with fleets } \\
\text { - Integrate into other business } \\
\text { models and activities e.g. } \\
\text { aggregation or renewables }\end{array}$ & $\begin{array}{l}\text { - Partner with larger } \\
\text { organisations; } \\
\text { - Seek out niches (e.g. } \\
\text { newbuild) and smaller scale } \\
\text { projects; and } \\
\text { - Use less expensive } \\
\text { technologies (e.g. shared loop } \\
\text { heat pumps) }\end{array}$ \\
\hline
\end{tabular}


This is a peer-reviewed, accepted author manuscript of the following research article: Braunholtz-Speight, T., McLachlan, C., Mander, S., Hannon, M., Hardy, J., Cairns, I., Sharmina, M., \& Manderson, E. (Accepted/In press). The long term future for community energy in Great Britain: a co-created vision of a thriving sector and steps towards realising it. Energy Research and Social Science.

Note: this table presents key features of the future business models based on the discussions at the Backcasting workshops (see Methods section) and subsequent analysis. The initial outlines that were used to stimulate debate at those workshops can be found in the Appendix. The actions suggested to overcome the barriers are drawn from the more detailed discussion in Section 5 below; these and more actions are summarised in Table 4. 
This is a peer-reviewed, accepted author manuscript of the following research article: BraunholtzSpeight, T., McLachlan, C., Mander, S., Hannon, M., Hardy, J., Cairns, I., Sharmina, M., \& Manderson, E. (Accepted/In press). The long term future for community energy in Great Britain: a co-created vision of a thriving sector and steps towards realising it. Energy Research and Social Science.

\subsection{Organisation, scale and community: the Community Energy Confederation}

Overall, the vision suggests a shift in the geographical and institutional boundaries of community energy business models. Currently in GB, the community energy sector is composed largely of local organisations, engaging with different customers depending on the nature of their operations. Those community energy organisations providing energy efficiency services, a minority in the sector, work with local households and small businesses. Those generating renewable electricity, which are the majority, may sell all their electricity to energy utilities via the grid: however, smaller scale renewables projects often also sell some electricity to a local "technology host" [53] e.g. from solar PV on the roof of a school or a factory) [48] and then export the surplus to the grid.

Two shifts are apparent in the new business models described above, in terms of customer segments, and in scale of operations. Firstly, there is a greater emphasis on business models focussed on individuals and households as customers, driven by their greater importance in the operation of a future more decentralised energy system (as mentioned in 4.1 above). All of the future business models above involve community energy organisations engaging directly with end users of energy, whether that energy is in the form of electricity, non-electric heating, or transport. Secondly, both the Aggregator and Mobility models would likely operate over a large geographical scale than is currently the case for community energy; the former to reach sufficient volumes of revenue to be sustainable, the latter to fit with its customers' travel habits.

Local scale operations are felt by many to be a key strength of community energy organisations. Participants felt that community organisations' embeddedness within their communities was crucial for generating the trust and local knowledge that would give community energy an advantage in a future consumer-centric energy system:

"the community bit is around trust and engaging with local people ... that's why the community aggregator really potentially could add value" Participant, London workshop

However, there is a tension between this emphasis on local embeddedness, and the drive to expand geographically in the Aggregator and Mobility business models mentioned above. Small scale also brings challenges in accessing technical and financial resources $[54,55]$ and limits the contribution of any one project to the energy transition. Unsurprisingly, debates over the best scale for community energy projects are a perennial feature of the sector (e.g. $[56,57])$. 
This is a peer-reviewed, accepted author manuscript of the following research article: BraunholtzSpeight, T., McLachlan, C., Mander, S., Hannon, M., Hardy, J., Cairns, I., Sharmina, M., \& Manderson, E. (Accepted/In press). The long term future for community energy in Great Britain: a co-created vision of a thriving sector and steps towards realising it. Energy Research and Social Science.

Consequently, we addressed this issue in the materials presented to workshop participants, and outlined a Renewable Electricity Network business model. Its purpose would be able to enable members to obtain a better price for their electricity through selling in larger volumes, and mixing different technologies to offer more consistent generation; and to pool funds for reinvestment in a range of projects and scales, from helping new member coops get started, to developing (or buying a stake in) offshore wind farms.

During the course of the workshops, this proposal became modified in two ways. Firstly, the word 'network' was interpreted as very top-down, and rejected by participants. We replaced it with 'Federation' to emphasise member control, and have since changed this again, to 'Confederation', to reflect participants' preference for local control over the central body (see 4.4 below and [58]). Secondly, it became clear that, while many participants saw advantages in such a Federation for renewable electricity generation, they felt it might be most needed to support the Local Energy Aggregator and Low Carbon Mobility business models (below). Inevitably, there will be a lower volume of flexible demand than of generation in the system. The ability to aggregate small local volumes of flexible demand into larger scale offers might be key to community aggregators' viability. The customer value proposition of the Low Carbon Mobility model would also be enhanced if the app gave access to community transport options in different areas across the UK, as some participants reported is already emerging among the RESCoop network in Europe ${ }^{10}$. The finalised Community Energy Confederation business model outline can be found in Table 2.

\subsection{Ownership, governance and organisational form}

Community ownership and governance are key differentiating features of community energy to date, and we explored what organisational forms might be needed to run these future business models. Participants affirmed that goals of democratic control and energy justice were fundamental to community energy: yet they were reluctant to prescribe particular legal and institutional structures for local community energy organisations. Instead, they took a pragmatic, context-driven approach. Building on existing community organisations was seen as key to expanding the sector, as illustrated by this quotation from the Edinburgh workshop as to what organisational form an organisation running a Local Energy Aggregator would take:

\footnotetext{
${ }^{10}$ https://www.themobilityfactory.eu/
} 
This is a peer-reviewed, accepted author manuscript of the following research article: BraunholtzSpeight, T., McLachlan, C., Mander, S., Hannon, M., Hardy, J., Cairns, I., Sharmina, M., \& Manderson, E. (Accepted/In press). The long term future for community energy in Great Britain: a co-created vision of a thriving sector and steps towards realising it. Energy Research and Social Science.

"First work with what's there! What existing organisations have built up - trust and local relationships."

Participant, Edinburgh workshop

This quotation perhaps implies that the Local Energy Aggregator business model will be run by community organisations, as opposed to public or private sector organisations. But that is not totally clear, and other participants were, in contrast, quite clear about the possibility of cross-sector partnerships being important for the long term growth of community energy. For example, there were positive statements about working with the public sector, and in particular local authorities:

"I think it's really interesting looking at how public ownership could be a very different thing to centralised, national government control of everything. And the role of community energy within a publicly owned wider energy system."

Participant, Cardiff workshop

That said, there were limits to this pragmatism as to how community energy could be organised: the organisational means could not conflict with social and environmental ends. This tension surfaced particularly in in debates about partnering with the private sector. While many community energy organisations currently work with local private sector companies (e.g. installing solar panels on the roofs of factories), suggestions of deeper engagement with the private sector provoked a mixed response. Thus, in discussions about the Confederation, there was broad support for structuring the Confederation as a cooperative of community energy groups, with strong accountability of the governing body to member groups. In contrast, when some participants suggested that a private company or energy utility could be contracted to provide marketing and administrative services for Confederation members, or even become a partner, other participants reacted with caution:

"as soon as you do that you reintroduce the profit motive - they will soak up all the value in the middle"

Participant, London workshop.

Here, the speaker associates the energy private sector with the concept of "the profit motive", implicitly in contrast to the social and environmental motivations typically reported by community energy practitioners[59]. We will return to questions of partnerships, governance and institutional structures in the Discussion. 
This is a peer-reviewed, accepted author manuscript of the following research article: BraunholtzSpeight, T., McLachlan, C., Mander, S., Hannon, M., Hardy, J., Cairns, I., Sharmina, M., \& Manderson, E. (Accepted/In press). The long term future for community energy in Great Britain: a co-created vision of a thriving sector and steps towards realising it. Energy Research and Social Science.

\section{Realising the vision: key actors and actions}

In this section we look at how the vision outlined in the previous section might be realised. Implicit in this is the recognition that there are barriers in the present day GB energy system to realising the vision, and operating the future business models. We present the actions and societal changes, which participants felt were needed to overcome these barriers and lead to the widespread adoption of the future business models by community-led organisations. We organise these steps and changes, firstly, by the actor or section of society that is making the change: community energy; central government; other levels of government; and the private sector. Secondly, under each of these actor headings, we say whether participants considered these changes needed to take place in the short term (next $2-3$ years) or the medium term (up to 2030). The relationship between these changes, and the potential future business models outlined in the previous section, is noted and discussed as appropriate throughout the section, and summarised in Table 4, and explored in detail in the rest of this section.

Note that, while we have indicated in the Table how the growth of District Heat Network business models might be enabled by various actions, workshop participants chose not to elaborate a detailed pathway for this business model. Nevertheless, they were clear that community heat should be part of the co-created long term vision. This apparent contradiction can be interpreted as revealing the participants' awareness of the importance of low carbon heating in social and environmental terms, but also their uncertainty as to how the decarbonisation of heating is to be achieved. This likely reflects wider uncertainty and under-developed public policy regarding the future of heating. 
This is a peer-reviewed, accepted author manuscript of the following research article: BraunholtzSpeight, T., McLachlan, C., Mander, S., Hannon, M., Hardy, J., Cairns, I., Sharmina, M., \& Manderson, E. (Accepted/In press). The long term future for community energy in Great Britain: a co-created vision of a thriving sector and steps towards realising it. Energy Research and Social Science.

Table 4: How different actors can contribute to the adoption of different future community energy business models

\begin{tabular}{|c|c|c|c|c|c|}
\hline Actor/Action & $\begin{array}{l}\text { Community } \\
\text { Renewable } \\
\text { Electricity } \\
\text { Company }\end{array}$ & $\begin{array}{l}\text { Local } \\
\text { Energy } \\
\text { Aggregator }\end{array}$ & $\begin{array}{l}\text { Energy } \\
\text { Saving } \\
\text { Services }\end{array}$ & $\begin{array}{l}\text { Low } \\
\text { Carbon } \\
\text { Mobility }\end{array}$ & $\begin{array}{l}\text { District } \\
\text { Heat } \\
\text { Network }\end{array}$ \\
\hline \multicolumn{6}{|l|}{ Central government } \\
\hline Detailed sector-specific decarbonisation targets & $\mathrm{x}$ & $\mathrm{x}$ & $\mathrm{x}$ & $\mathrm{x}$ & $x$ \\
\hline Joined-up energy regulation & $\mathrm{X}$ & $\mathrm{X}$ & $\mathrm{X}$ & $\mathrm{x}$ & $\mathrm{x}$ \\
\hline $\begin{array}{l}\text { Grant fund retrofit - long term programme for } \\
\text { those who can't afford }\end{array}$ & & & $x$ & & \\
\hline Keep flexibility markets open to smaller actors & & $x$ & & & \\
\hline \multicolumn{6}{|l|}{ Community energy } \\
\hline $\begin{array}{l}\text { Lobby government with ambitious vision for } \\
\text { community energy }\end{array}$ & $x$ & $x$ & $\mathrm{x}$ & $x$ & $\mathrm{x}$ \\
\hline $\begin{array}{l}\text { Form a Confederation to support member } \\
\text { organisations with economies of scale and } \\
\text { learning, and access new markets }\end{array}$ & $x$ & $\mathrm{x}$ & $\mathrm{x}$ & $\mathrm{x}$ & $\mathrm{x}$ \\
\hline $\begin{array}{l}\text { Work with residents to resolve expensive-to- } \\
\text { retrofit old or poor quality housing }\end{array}$ & & & $x$ & & \\
\hline $\begin{array}{l}\text { Network with wider third sector to build } \\
\text { partnerships }\end{array}$ & & $x$ & $x$ & $x$ & $x$ \\
\hline \multicolumn{6}{|l|}{ Local government } \\
\hline Incentivise buying of CE generation & $\mathrm{X}$ & & & & \\
\hline Purchase community-generated electricity & $\mathrm{X}$ & & & & \\
\hline Invest in community projects & $\mathrm{x}$ & $\mathrm{x}$ & $\mathrm{x}$ & $\mathrm{x}$ & $\mathrm{x}$ \\
\hline Make sites available for community renewables & $\mathrm{x}$ & & & & \\
\hline $\begin{array}{l}\text { Maximise local economic gain from projects e.g. } \\
\text { procurement, training. }\end{array}$ & $\mathrm{x}$ & $\mathrm{x}$ & $\mathrm{x}$ & $\mathrm{x}$ & $\mathrm{x}$ \\
\hline \multicolumn{6}{|l|}{ Wider third sector } \\
\hline $\begin{array}{l}\text { Housing groups to install energy saving, PV or } \\
\text { heat tech, establish aggregator }\end{array}$ & $x$ & $x$ & $x$ & $x$ & $x$ \\
\hline $\begin{array}{l}\text { Community transport or taxi coops to use EVs + } \\
\text { community charging }\end{array}$ & & $\mathrm{x}$ & & $\mathrm{x}$ & \\
\hline \multicolumn{6}{|l|}{ Private sector } \\
\hline $\begin{array}{l}\text { Energy SMEs: Joint advocacy to government for } \\
\text { decarbonisation }\end{array}$ & $x$ & $x$ & $x$ & $x$ & $x$ \\
\hline $\begin{array}{l}\text { Energy SMEs: Partnerships on renewables } \\
\text { projects }\end{array}$ & $x$ & & & & \\
\hline $\begin{array}{l}\text { System operators: promote level playing field for } \\
\text { community energy e.g. provide assistance and } \\
\text { training }\end{array}$ & $x$ & $x$ & $x$ & $x$ & $x$ \\
\hline $\begin{array}{l}\text { Wider private sector: Buy community energy and } \\
\text { partner with community organisations }\end{array}$ & $x$ & $x$ & & & \\
\hline \multicolumn{6}{|l|}{ Finance sector } \\
\hline Long-term patient capital to community projects & $\mathrm{X}$ & $\mathrm{x}$ & & $\mathrm{x}$ & $\mathrm{X}$ \\
\hline Low or zero interest loans for retrofit & & & $\mathrm{X}$ & & \\
\hline $\begin{array}{l}\text { Develop regional and local banking institutions } \\
\text { lending for local sustainable development }\end{array}$ & $x$ & $x$ & $\mathrm{x}$ & $\mathrm{x}$ & $\mathrm{x}$ \\
\hline
\end{tabular}


This is a peer-reviewed, accepted author manuscript of the following research article: BraunholtzSpeight, T., McLachlan, C., Mander, S., Hannon, M., Hardy, J., Cairns, I., Sharmina, M., \& Manderson, E. (Accepted/In press). The long term future for community energy in Great Britain: a co-created vision of a thriving sector and steps towards realising it. Energy Research and Social Science.

\subsection{Central government}

Central government was seen as a key player in determining the future of community energy. Participants identified several high-level principles for energy policy, which would assist the development of all the future community energy business models

\subsubsection{Short Term}

The first priority was to "take climate change seriously", which in practice was felt to mean setting detailed zero carbon targets for specific economic sectors, or geographical areas: not just a single UK-wide target. Secondly, making sure there is space for smaller actors in the energy transition. This would require a mix of regulatory change to encourage local electricity supply and local energy markets; and ensuring regulation and technical standards keep energy data systems accessible to smaller actors, perhaps by keeping them open source. Thirdly, a wholesale overhaul of the fundamental principles of energy regulation, so that the co-benefits community (and local) energy brings to other policy areas (health, local economies etc.) is recognised and valued. This suggestion reflects a recognition in the sector that, although 'the regulators' are seen by some as being obstructive to community energy, this is at least in part because they are bound by their duties that make little allowance for the sector on the basis of the wider co-benefits it offers (although recent Ofgem publications suggest that this may be changing [60]). All of these changes were felt to have implications for all of the future business models (see Table 4).

Financial support was seen as important for the development of new Community Renewable Electricity Companies, although the form that this should take was debated. Grants or soft loans ${ }^{11}$ for project development were widely supported, with Scotland's CARES scheme offering one model for this. On the other hand, there was a feeling that price support of the level and duration (20 years) offered by the Feed-in Tariff scheme was no longer politically possible. Nevertheless, even a shorter-duration low level price guarantee was seen as enormously valuable to de-risk renewable energy projects, and perhaps politically viable in the longer term, if targeted at projects that could demonstrate social benefit.

New financial support was also seen as critical to the Energy Saving Services business model. Here there was agreement that government should commit to a comprehensive funding programme, including grants, for retrofitting the UK's energy inefficient housing stock. This programme was not envisaged as being exclusive to community energy groups, but participants felt that their long term

\footnotetext{
${ }^{11} \mathrm{~A}$ 'soft loan' is a loan that is offered at better terms than prevailing in the market: typically, at a lower interest rate, and possibly with provision for cancellation or deferment in some circumstances.
} 
This is a peer-reviewed, accepted author manuscript of the following research article: BraunholtzSpeight, T., McLachlan, C., Mander, S., Hannon, M., Hardy, J., Cairns, I., Sharmina, M., \& Manderson, E. (Accepted/In press). The long term future for community energy in Great Britain: a co-created vision of a thriving sector and steps towards realising it. Energy Research and Social Science.

local presence generated local knowledge, trust and accountability that meant they would be important actors in its delivery. As noted earlier in the paper, participants felt that there isn't a viable business model for pay-as-you-save retrofit for poorer households. Instead, warm and decent housing should simply be seen as a public good for which the state should pay. This meant that grants were essential if low income households were to benefit:

\section{"I don't see how you're going to really eradicate fuel poverty without grant support" (participant, London workshop)}

While this programme was felt to be urgently needed, and therefore a priority for short term government action, participants also stressed that it needed to be a long term measure, as the scale of the retrofit challenge was huge and would take decades to address.

\subsubsection{Medium Term}

In the medium term, regulation to enable the creation of local energy markets was seen as a key step for central government to take. Participants recognised that this would be a complex and major undertaking, and so not likely to happen in the short term, but felt that it was feasible in the medium term, as steps towards it are already happening[61] and that it would be a major facilitator of the expansion of Community Renewable Electricity Companies and Local Energy Aggregators.

Another point made about the medium term was that the retrofit programme, begun in the short term, should be maintained - putting an end to stop-start funding programmes that had characterised this sector. Participants also felt that in the medium term there was scope for increasing ambition in the regulation of energy efficiency standards for new housing, up to Passivhaus ${ }^{12}$ standard for all new builds.

\subsection{Community Energy}

\subsubsection{Short Term}

Looking across all the business models, participants saw central government policy as a key factor shaping the direction of the energy transition. While specific measures for government to take identified have been outlined under 'central government' above, it was clear that CE sector actors could play an active role in convincing government of the benefits of community energy. A twintrack approach emerged: on the one hand, assembling quantitative evidence on the benefits of

\footnotetext{
${ }^{12}$ Passivhaus, or Passive House, is an international building energy efficiency standard. See https://passivehouse.com/
} 
This is a peer-reviewed, accepted author manuscript of the following research article: BraunholtzSpeight, T., McLachlan, C., Mander, S., Hannon, M., Hardy, J., Cairns, I., Sharmina, M., \& Manderson, E. (Accepted/In press). The long term future for community energy in Great Britain: a co-created vision of a thriving sector and steps towards realising it. Energy Research and Social Science.

existing and new projects, and on the other, further developing a positive narrative around the sector on its potential to support delivery of the energy transition.

Regarding the evidence, it is notable that there have recently been some initiatives from the sector aimed at gathering standardised impact data $[62,63]$. As for the narrative, arguably it is already positive, but also limiting, with an implicit assumption that community energy is small scale. If the sector's ambition is to be a significant player in a transformed low carbon energy system, this ambition needs to be explicitly stated, and its feasibility demonstrated, in the types of plans and demands made.

As regards specific steps towards operationalising the future business models outlined earlier, the most urgent priority identified for the short term was for groups to decide whether or not they were interested in the Low Carbon Mobility business model. Some workshop participants felt that it was already too late for community energy to become substantially involved in the fast developing electric transport sector. However, others advocated for groups to act as soon as possible to: develop knowledge transfer networks among themselves to facilitate learning of best-practice; contact other potential business partners, particularly community transport or housing groups, but also sympathetic electric transport SMEs; and engage with government particularly at local or devolved levels. On this latter point, some suggested that air quality as much as climate change can be a driver for public policy to support moving away from internal combustion engines. However, overall a need for training and bringing relevant skills into the community sector was identified, but it was not clear who would provide this.

\subsubsection{Medium Term}

Further steps towards several of the business models were considered feasible in the medium term. It was hoped that, given policy and regulatory change (see 'central government' below), it might be possible for Community Renewable Electricity Companies to become local energy retailers, selling energy direct to local households and businesses. For new subsidy free renewables, a national Community Energy Confederation could provide a route to market to sell surplus local generation. In addition, the contracts for some early community renewables projects might have expired, allowing those groups - provided that their technology was still working - to sell through the Federation too.

Participants envisaged a future where central government provides substantial funding for a long term programme of energy efficiency schemes. In the medium term, Energy Saving Services business models funded through such schemes will have accumulated a track record of experience and achievement, and might even be expanding. One issue identified here was what to do with old and 
This is a peer-reviewed, accepted author manuscript of the following research article: BraunholtzSpeight, T., McLachlan, C., Mander, S., Hannon, M., Hardy, J., Cairns, I., Sharmina, M., \& Manderson, E. (Accepted/In press). The long term future for community energy in Great Britain: a co-created vision of a thriving sector and steps towards realising it. Energy Research and Social Science.

expensive-to-retrofit properties, particularly after many easy to treat properties have been

completed. Workshop participants suggested that demolition and replacement might have to be the way forward, and that community organisations were best placed to ensure that such redevelopment was done with the interests and wellbeing of existing residents represented - rather than leading to 'low carbon gentrification'.

Finally, it was felt that medium term was when it would become apparent whether community groups running Low Carbon Mobility businesses will be widespread across the UK; or whether they will be confined to a few niche areas that are unattractive to commercial operators - more sparsely populated rural areas, for example.

\subsection{Local government}

Local authorities were seen as promising partners in realising the vision of an expanded community energy sector. There were many steps in which participants (including some with direct experience of existing community-local authority partnerships) felt that local authorities could take to help build the sector.

Firstly, local authorities often own large numbers of buildings and substantial areas of land. These could be promising sites for post-FITs renewable energy generation[48], with implications for Community Renewable Electricity Companies. In several cases (e.g. Edinburgh [64]) local authorities have already made roofspace available for community solar PV; although where Private Finance Initiative (PFI) ${ }^{13}$ contracts have complicated ownership of the public estate, this might be more difficult. Planning powers could also be used to support local renewable development and other activities e.g. requirements for new housing developments to incorporate EV charge points could help the Low Carbon Mobility business model.

Many felt that they could go further to support existing community energy generation, by purchasing grid-supplied community generated energy, rather than just that which is generated 'behind the meter' on local authority buildings. Other local public sector bodies (e.g. NHS Trusts) could do this too. The timescale for this to become possible would depend on the development of regulations regarding local energy markets, and the details of each public sector body's energy

\footnotetext{
${ }^{13}$ The Private Finance Initiative was a UK government programme whereby new public buildings (housing, schools, hospitals etc.) were built and financed by private companies, who were then paid back by the public sector on complex long-term contracts.
} 
This is a peer-reviewed, accepted author manuscript of the following research article: BraunholtzSpeight, T., McLachlan, C., Mander, S., Hannon, M., Hardy, J., Cairns, I., Sharmina, M., \& Manderson, E. (Accepted/In press). The long term future for community energy in Great Britain: a co-created vision of a thriving sector and steps towards realising it. Energy Research and Social Science. procurement contracts. Local authorities could also use their powers to design business rates ${ }^{14}$ to encourage local businesses to buy local energy.

On the finance and resources areas of business models, local authorities were seen as having access to public sector finance at below commercial rates, and there might be ways to use and 'recycle' this to fund community-led projects, or joint ventures. Local authority staff and finance might also be used to support Local Energy Aggregators, perhaps tied into a digital inclusion or fuel poverty strategy.

\subsection{Private sector}

Participants' suggestions for the private sector can be divided into actions for energy companies to take, actions for the finance sector to take, and actions for the wider private sector. For energy companies, participants felt that smaller energy businesses could make common cause with community energy more often. This could be in order to advance policy and regulatory change through joint lobbying in favour of the interests of smaller actors; or through actual partnerships on projects. Looking at larger businesses, there was discussion about the role of 'system operators' the companies that own and operate the distribution and transmission networks. Many felt that more needed to be done to ensure that they were 'neutral' and promoted the interests of smaller actors, despite some improvement by some operators. Some suggested that a publicly-owned system operator could more easily be made to act in this wider public interest.

Actions for the finance sector to take in the short term were for lenders to move away from shortterm returns towards providing more long-term capital to community projects. There was felt to be a particular need for low or zero interest loans for retrofit, to reflect the long payback timescales of most energy efficiency schemes. A more medium term hope was that Britain's existing regional and local banking institutions could expand, or new institutions developed, and prioritise lending for local sustainable development - in a similar fashion to German regional development banks.

Looking to the private sector more generally, there was a hope that companies would increasingly purchase community-generated renewable electricity, and see 'buying community' as part of their marketing and corporate social responsibility strategies. In the short term, this might be restricted to companies with suitable sites for renewable generation (one existing example being the Marks and Spencer Energy Society). In the medium term, however, regulations permitting local energy markets could open up opportunities for community energy generators to sell to local businesses via the

14 "Business rates" are property taxes levied by UK local authorities on businesses in their area. 
This is a peer-reviewed, accepted author manuscript of the following research article: BraunholtzSpeight, T., McLachlan, C., Mander, S., Hannon, M., Hardy, J., Cairns, I., Sharmina, M., \& Manderson, E. (Accepted/In press). The long term future for community energy in Great Britain: a co-created vision of a thriving sector and steps towards realising it. Energy Research and Social Science.

distribution network. Alternatively, if a larger scale Community Energy Confederation emerged as a trading body, it might negotiate PPAs with private sector companies.

\subsection{Wider third sector}

By the medium term, participants hoped that community groups active in other areas of infrastructure - from development trusts to land and housing groups - would be increasingly partnering with community energy to run some of the more citizen-focussed new business models. Particular opportunities for collaboration were identified with housing groups, around: installation of renewable energy in new or refurbished housing developments; organising residents' flexible demand capacity through a Local Energy Aggregator; and installing EV charging or more ambitious transport schemes through a Low Carbon Mobility model. Another possibility for Low Carbon Mobility was working with taxi driver cooperatives, or community transport schemes.

\section{Discussion}

In this section we will step back from the detail presented in the last two sections, and synthesise our findings. We find that our research: suggests that the institutional and spatial boundaries of community energy need to change; highlights the sector' pragmatic attitude to the technological aspects of the energy transition; and it suggests that community energy's role in delivering social and environmental co-benefits, in line with the concept of a just transition, may be its key contribution to the energy transition.

\subsection{The institutional and spatial boundaries of community energy}

\section{organisations need to change}

It is clear that a thriving community energy sector will be expanded in various ways from the current situation. The Community Energy Confederation is designed to play a major role in helping locallybased organisations interact with the wider energy system. This could allow them to benefit from economies of scale, and opportunities in national or regional markets, that have previously been inaccessible; while retaining their local identity and membership. And as well as expanding the spatial boundaries of their work, our research also suggests that practitioners are keen to expand their activities into other parts of the energy system; and that they see working with other community organisations and partners in other sectors as a key part of the future. 
This is a peer-reviewed, accepted author manuscript of the following research article: BraunholtzSpeight, T., McLachlan, C., Mander, S., Hannon, M., Hardy, J., Cairns, I., Sharmina, M., \& Manderson, E. (Accepted/In press). The long term future for community energy in Great Britain: a co-created vision of a thriving sector and steps towards realising it. Energy Research and Social Science.

Such a future builds on existing trends. Already, several community energy organisations work in multiple locations. Notably the Energy4All cooperative ${ }^{15}$ is itself formed of local energy cooperatives, gaining economies of scale and learning from the support of a central hub - although they do not pool generation to sell on national markets as the Confederation members would. And while they are primarily engaged in advocacy and support rather than energy projects of their own, there are already umbrella groups at national level: Community Energy Scotland (CES), Community Energy Wales (CEW) and Community Energy England (CEE); and at regional level in England e.g. Community Energy South. Again, community organisations with a wide remit are already engaged in 'community energy', from the 'small is beautiful' village hall or sports club doing biomass boiler or solar roof[65] , to development trusts using wind turbine revenue to pay for housing[66].

One implication of the diversification of business models and institutional forms in our vision is an increasing convergence between the shape of the community energy sectors in Scotland, Wales and England. Historically, Scotland and Wales have seen greater focus on community wind and hydro projects, with solar more common in England. And while in England the sector has been more characterised by environmentally-orientated cooperatives, the integration of energy activities into the work of multi-sectoral community development trusts has long been a feature of community energy in Scotland[65, 67]. Yet if opportunities for local energy generation and trading expand, more housing and transport groups may crossover with community energy to produce further multisectoral community partnerships in other parts of GB. Equally, a shift towards more customercentric business models may also drive convergence between the nations of $\mathrm{GB}$, as the nature of the renewable resource becomes a less important factor in community energy.

Another hybridisation, and perhaps a more profound one, is that between local authorities and community energy. Increasingly close collaboration between public and third sectors could create a more coherent "civic energy sector" (Hall et al 2016). Community energy might contribute technical and fundraising expertise, small actor agility, local knowledge, and the trust that comes from deep engagement with small groups of citizens, to complement local authorities' access to physical and human resources, regulatory and planning role, and their capacity for broad outreach to large groups of citizens.

Again, there are several examples of local authorities and community groups already working together under various institutional arrangements (e.g. Edinburgh Community Solar Coop, Plymouth

\footnotetext{
${ }^{15}$ www.energy4all.co.uk
} 
This is a peer-reviewed, accepted author manuscript of the following research article: BraunholtzSpeight, T., McLachlan, C., Mander, S., Hannon, M., Hardy, J., Cairns, I., Sharmina, M., \& Manderson, E. (Accepted/In press). The long term future for community energy in Great Britain: a co-created vision of a thriving sector and steps towards realising it. Energy Research and Social Science.

Energy Community, Swansea Community Energy and Enterprise Scheme, Gwent Energy CIC). However, despite this, community energy practitioners also expressed frustration over failed attempts to work with the local authorities. Sometimes, they felt that officials treated them as amateurish and did not take them seriously; in other cases, projects appeared to sink under the weight of procurement regulation or perceived opaque institutional decision-making. A third factor may be that, as the quotation above suggests, practitioners see local authorities as much closer to community energy's level of action than devolved governments, and in some sense 'natural' allies:

"The local authority are 'them' and we're 'us'. And to join the two would be such a positive thing. Because that's the definition of local action, isn't it?"

Participant, Cardiff workshop

Debates around working with the private sector revealed caution from some participants, who felt that "the profit motive" could conflict with the social and environmental goals of community energy (as noted in Section 4.4 above). Nevertheless, participants also saw a role for tactical alliances, at the very least, with small energy companies. Others felt that formal partnerships on projects could work; and again, this is a feature of some community energy already. While the literature suggests that community-private partnerships may not be easy[68], on the other hand, Energy4All have a longestablished partnership with Falck Renewables, and have developed several projects whose ownership is split between Falck and local cooperatives ${ }^{16}$.

The existence of institutional and spatial hybrids shows that community energy is perhaps more flexible and diverse than might be currently appreciated by actors looking to deliver the wider energy transition. Despite some wariness of central authority and protectiveness of local roots, workshop participants were generally very willing to think across established boundaries. The future vision presented here represents the rapid growth of an existing trend, rather than a revolution. While often associated with locally-focussed small-scale action "typically below the level of local government"[69], in practice it already exhibits considerable pragmatism in the pursuit of the democratisation and decarbonisation of the energy system. This is a theme that we explore further in the next subsection.

\subsection{The community energy sector is technologically pragmatic and flexible}

Our research also highlights the pragmatism and adaptability of community energy with regards to energy technologies and business models. Different groups have different mixes of motivations. But

${ }^{16}$ See e.g. https://auchrobert.coop/, https://boyndie.coop/, and https://www.kilbraur.coop/. 
This is a peer-reviewed, accepted author manuscript of the following research article: BraunholtzSpeight, T., McLachlan, C., Mander, S., Hannon, M., Hardy, J., Cairns, I., Sharmina, M., \& Manderson, E. (Accepted/In press). The long term future for community energy in Great Britain: a co-created vision of a thriving sector and steps towards realising it. Energy Research and Social Science.

of the $4 \mathrm{Ds}$, decarbonisation and democratisation - broadly understood - are key. They have formed around these motivations, and the technologies and trading approaches they adopt are generally just a means to an end.

Decarbonisation sets some limits on this pragmatism. The community energy sector does not champion fracking, for example. Further, groups inevitably develop interests that are to an extent tied to their existing commitments and expertise. Thus, as the sector is currently dominated by small-scale renewable electricity generation, it was not surprising to find widespread enthusiasm for seeing more of this in the future. But participants also emphasised that they are prepared to learn and adapt, and that even the current mainstream of community energy was new once, as this quotation illustrates:

"the whole area [smart grids] is very technically difficult and very specific [....but] we started the big turbines and we had no idea how it was going to work, but we learned the skills to be able to do that."

Participant, Edinburgh workshop

We suggest that this pragmatism and adaptability has emerged, at least in part, from their experience of surviving as small, local organisations within the UK energy sector, which is dominated by large organisations and national level policy. We further suggest that this lay behind workshop participants' approach to timescales, and the relative lack of medium term actions in Section 5. Participants were keen, and very able, to elaborate a long-term vision of the role(s) they thought community energy could play in a future energy system; although they did not want the 'long term' to be many decades away. They also had many concrete suggestions for change in the short term, and what the first steps might be on the path towards that long term vision. They tended to focus on these two extremes, however, and were somewhat reluctant to map out the whole journey. This becomes understandable within the context of their experience to date. Adaptability has been key to survival: committing to a detailed long-term plan has not been feasible.

\subsection{Community energy has the potential to deliver a more successful and 'just' energy transition but policy changes are needed to realise this}

The energy transition will require active citizen involvement across a range of energy vectors[70]. Community energy organisations, as specialists in engaging citizens in energy issues, could play an important role. Many of the participants in our workshops suggested that involving community energy was a necessary part of the energy transition. They frequently pointed to the slow progress 
This is a peer-reviewed, accepted author manuscript of the following research article: BraunholtzSpeight, T., McLachlan, C., Mander, S., Hannon, M., Hardy, J., Cairns, I., Sharmina, M., \& Manderson, E. (Accepted/In press). The long term future for community energy in Great Britain: a co-created vision of a thriving sector and steps towards realising it. Energy Research and Social Science.

of the commercially-led "rollout" of domestic smart metering in the UK as evidence that, without specialist community engagement, the technology required for a more flexible and decentralised future energy system would not be deployed in a way that engenders citizen acceptance and support. In the long term, practitioners feel that there is great potential for community energy to grow, and contribute more significantly to the energy transition. They highlighted their organisations' engagement with their communities, and long term commitment to a place: the local trust and knowledge generated by both of these could be advantageous in delivering and managing a more decentralised system[48].

How far a significant increase in the role of community energy is necessary for the energy transition to be a success, and how success might be judged, is more open to debate. Other studies of energy system futures suggest a community energy approach is only one possible form that the transition may take, and that alternatives - based on a centralised state approach, or a decentralised private sector approach - may prevail $[27,34,36]$.

However, it may be that the concept of 'just transition' highlights the particular contribution to the energy transition for which community energy is necessary. This concept is related to but broader than 'energy justice'[71], and is broadly concerned with issues of social equity in the energy transition. With origins in debates about the social impact of environmental policy in the 1970s, it has developed and gained increasing prominence in policy in recent years[25], and linked to community energy [72]; within Great Britain, Scotland established a Just Transition Commission in $2019^{17}$. While most of our workshop participants did not use the term - although some did -a concern with "fairness", "benefit for all" and "no-one left behind" were common themes in workshop discussions. These issues arose particularly in relation to what, in the initial future business models (see Appendix), we called the "community difference": how a community approach to energy could add value, and for whom. Also, one of the arguments made in favour of the Confederation during the workshops was that a multi-locality organisation could help address spatial inequalities in renewable resource endowments or fundraising capacity. Yet, the long list of steps needed to realise the vision outlined earlier in the paper shows that the expanded community energy sector presented in our vision is unlikely to emerge without purposeful intervention by a range of actors who see the value the sector could bring to the energy transition.

\footnotetext{
${ }^{17}$ https://www.gov.scot/groups/just-transition-commission/
} 
This is a peer-reviewed, accepted author manuscript of the following research article: BraunholtzSpeight, T., McLachlan, C., Mander, S., Hannon, M., Hardy, J., Cairns, I., Sharmina, M., \& Manderson, E. (Accepted/In press). The long term future for community energy in Great Britain: a co-created vision of a thriving sector and steps towards realising it. Energy Research and Social Science.

Given its importance in the highly regulated energy sector, government has a key role to play in including community energy, and energy justice, in its vision for the energy sector as a whole. It is notable that the level of government attention to community energy, and ambition for it, is different across the different nations of GB. The Community Energy Strategy produced by the UK government in London in 2014 has been little referred to since a change of government in 2015, and, as outlined in the Introduction, energy policy changes since then have largely been negative for community energy. In contrast, in both Scotland[73] and Wales[74], the devolved governments have set targets for local ownership of renewable energy which explicitly include community ownership, and established innovative mechanisms to link environmental and social justice - Scotland's Just Transition Commission referred to above, and the Welsh Wellbeing of Future Generations Act ${ }^{18}$. While many possibilities remain in England - notably community energy participation in the government's flagship Prospering from the Energy Revolution programme ${ }^{19}$ - in the short term, Scotland and Wales may be the national policy contexts that are most promising for community energy innovation. In the longer term, we suggest that a convergence of English or GB-level policy with these Scottish and Welsh approaches, and a further 'joining up' of GB level energy regulation with social and environmental policy goals (as called for in our workshops), will be necessary if our vision is to be realised across Great Britain.

\section{Conclusion}

\subsection{Key findings}

Drawing on a series of stakeholder workshops, this paper has presented a co-created vision that explores the potential of the GB community energy sector in shaping and delivering the energy transition and how to realise that potential. The workshops were held across Great Britain, with an invited selection of community energy practitioners and stakeholders. We worked with participants to co-create a vision where community organisations are active in many more areas of the GB energy system than they are today, and are increasingly working across localities and sectors to drive a just transition.

Our research highlights three key points about the future of community energy in GB. Firstly, the institutional and spatial character of community energy would need to change to realise our vision.

\footnotetext{
${ }^{18}$ https://www.futuregenerations.wales/

${ }^{19}$ https://project-leo.co.uk/
} 
This is a peer-reviewed, accepted author manuscript of the following research article: BraunholtzSpeight, T., McLachlan, C., Mander, S., Hannon, M., Hardy, J., Cairns, I., Sharmina, M., \& Manderson, E. (Accepted/In press). The long term future for community energy in Great Britain: a co-created vision of a thriving sector and steps towards realising it. Energy Research and Social Science.

In the longer term, the boundaries of the community energy 'sector' may be more fuzzily defined and porous. Institutionally, partnership with other organisations -third, public and private sectormay be much more common. And spatially, the scales at which community energy operates would be more diverse. In particular, we suggest a Confederation of community energy groups may be a way to resolve the tension between achieving economies of scale, and preserving local groups' roots in their communities.

Secondly, the sector's pragmatic attitude to the technological aspects of the energy transition is notable. Technological change is one enabler of new business models, but the focus is always on social and environmental outcomes. Community energy activists have in the past adapted to new technologies and business models, and this adaptability may serve them well in the future.

Finally, we discuss on community energy's role in delivering social and environmental co-benefits, in line with the concept of a just transition. While a more consumer-centric and decentralised energy system arguably needs community engagement just in order to ensure it works smoothly (as evidenced by the slow pace of the smart meter rollout), it may be in ensuring that such a system is equitable and serves everyone that community energy has a particular strength. Community groups' local knowledge, relationships and accountability could play an important role in shaping the social outcomes of the energy transition.

Achieving this vision will require policy and regulatory change by central government, and support from other actors across public, private and third sectors. Our research participants saw local authorities as potentially key players, as purchasers of community energy services and partners in developing local energy systems that work for all residents. But central government was also seen as important: in particular, for ensuring that energy regulation permits smaller actors to contribute to the energy transition, and guards against the formation of new digital energy monopolies. In this, community energy will have allies in many energy companies.

However, it will also require change from within the community energy sector itself: learning new technical skills, and developing new forms of organisation to combine the benefits of local knowledge and trust with the benefits of scale and partnerships. Finally, it will likely require the sector to make a bold case to central government, to convince policymakers of the desirability of a vision such as that presented in this paper, and of the need for them to take action to help realise it. The existence of Scotland's Just Transition Commission, and Wales' Wellbeing of Future Generations Act, can be used to bolster the case for action at GB level. We note also that Community Energy England has produced a 2030 Vision[75] that is an important step in making such a case. 
This is a peer-reviewed, accepted author manuscript of the following research article: BraunholtzSpeight, T., McLachlan, C., Mander, S., Hannon, M., Hardy, J., Cairns, I., Sharmina, M., \& Manderson, E. (Accepted/In press). The long term future for community energy in Great Britain: a co-created vision of a thriving sector and steps towards realising it. Energy Research and Social Science.

\subsection{Limits of the present study and areas for further research}

We believe that the research has produced a plausible long-term vision of a community energy sector that is significantly different from today's; nevertheless, in relation to some specific issues, it seems that participants struggled to think beyond "the problematic present" [42]. The suggestion (in section 5.1 above) that a long-term price guarantee like the Feed-in Tariff would never be feasible again is one example of this; their uncertainty as to how a District Heating Network business model might become widespread is another. Thus, while we feel that our use of a backcasting methodology to co-create the vision has largely been successful, we acknowledge some limitations to our findings.

Importantly, the research also raises questions worthy of greater exploration than has been possible in this paper. More work could be done on quantifying the potential future market opportunities for community energy organisations operating the business models outlined above, perhaps as has been done for some areas of the electricity system for larger actors[76]; the business model outlines themselves could be further developed and their potential operation scoped in greater detail. The detail and feasibility of the policy proposals from section 5 merits further examination. Also of relevance to policy making, the evidence base on existing and potential co-benefits of community energy, in terms of the sector's social and environmental impacts, could also benefit from further research[77].

\subsection{The future of community energy in Great Britain in wider context}

Another limitation of this research is its geographical scope: it was developed in and for the GB context. Therefore, we conclude by considering our vision and pathways in comparison with community energy in other national contexts. Four points stand out. Firstly, in several other European countries (e.g. Germany, Denmark, Belgium), local energy retail - a medium-term ambition for our Community Renewable Electricity Companies - already exists. Secondly, studies indicate that in these countries, local energy cooperatives and other forms of community energy are more significant actors in the energy system than they are in the UK[78-80]. Thirdly, supportive public policy and financial institutions have been important in the development of these systems. Finally, other research[9] points to the importance of a strong wider cooperative sector in explaining the size of the community energy sector. This recalls the more mutualised and localised economy envisaged in the wider context of our long term vision (section 4.1 above).

All of these studies suggest, firstly, that our future vision is plausible. A larger and more diverse GB community energy sector, pragmatic with regard to technological means, but committed to a just transition, would perhaps be not so much revolutionary as a further development of trends seen 
This is a peer-reviewed, accepted author manuscript of the following research article: BraunholtzSpeight, T., McLachlan, C., Mander, S., Hannon, M., Hardy, J., Cairns, I., Sharmina, M., \& Manderson, E. (Accepted/In press). The long term future for community energy in Great Britain: a co-created vision of a thriving sector and steps towards realising it. Energy Research and Social Science.

elsewhere in Europe. Secondly, it suggests that the changes in public policy and community energy interaction with other organisations outlined in our paper may indeed be important for growing the sector in Great Britain. 
This is a peer-reviewed, accepted author manuscript of the following research article: BraunholtzSpeight, T., McLachlan, C., Mander, S., Hannon, M., Hardy, J., Cairns, I., Sharmina, M., \& Manderson, E. (Accepted/In press). The long term future for community energy in Great Britain: a co-created vision of a thriving sector and steps towards realising it. Energy Research and Social Science.

\section{References}

1. Engie. Energy Transition. 2018 17.02.2020]; Available from: https://corporate.engie.be/en/energy-transition-2/.

2. Hoggett, R., Putting people at the heart of the energy system. , in IGov Roundtable on People at the Heart of the Energy System. 2018: London.

3. Lloyd, H.e., A Distributed Energy Future for the UK. 2018, IPPR: London.

4. Centrica and KPMG, The Future of our Energy Market. 2018, Centrica and KPMG: London.

5. $\quad$ Arup, Energy systems: a view from 2035. 2017, Arup: London.

6. Sandys, L., et al., A Strategy for a Modern Digitalised Energy System: Energy Data Taskforce Report. 2019, Energy Data Taskforce: London.

7. British Institute of Energy Economics. Consumers at the Heart of the Energy System? in BIEE Biennial Research Conference. 2018. Oxford.

8. Mitchell, C., Decentralising energy and communities, in Community Energy London Annual Conference. 2019: London.

9. Bauwens, T., B. Gotchev, and L. Holstenkamp, What drives the development of community energy in Europe? The case of wind power cooperatives. Energy Research and Social Science, 2016. 13: p. 12.

10. Herbes, C., et al., Responding to policy change: New business models for renewable energy cooperatives - Barriers perceived by cooperatives' members. Energy Policy, 2017. 109: p. 8295.

11. Kooij, H.-J., et al., Between grassroots and treetops: Community power and institutional dependence in the renewable energy sector in Denmark, Sweden and the Netherlands. Energy Research and Social Science, 2018. 37: p. 52-64.

12. Sweeney, S., J. Treat, and I.H. Shen, Transition in Trouble? The rise and fall of "community energy" in Europe, in TUED Working Papers. 2020, Trade Unions for Energy Democracy: New York.

13. Community Energy England and Community Energy Wales, State of the Sector 2019. 2019, CEE and CEW: Sheffield and Cardiff.

14. Braunholtz-Speight, T., et al., The Evolution of Community Energy in the UK, in UKERC Working Paper. 2018, UK Energy Research Centre: London.

15. Renewable Energy Association, REView: Renewable Energy View 2016. 2016, Renewable Energy Association: London.

16. Mirzania, P., Ford, A., Andrews, D., Ofori, G., Maidment, G., The impact of policy changes: The opportunities of Community Renewable Energy projects in the UK and the barriers they face. Energy Policy, 2019. 129: p. 1282-1296.

17. Roby, H. and S. Dibb, Future pathways to mainstreaming community energy. Energy Policy, 2019. 135.

18. Nolden, C., J. Barnes, and J. Nicholls, Community energy business model evolution: A review of solar photovoltaic developments in England. Renewable and Sustainable Energy Reviews, 2020. 122.

19. Kumar, C., Community Energy 2.0: the future role of local energy ownership in the UK. 2019, Green Alliance: London.

20. Atkinson, J., et al., Energy Community Aggregator Services. 2018, Carbon Coop and Regen: Manchester and Exeter.

21. National Grid, Future Energy Scenarios 2018. 2018, National Grid plc: Warwick.

22. IRENA, Global Energy Transformation: a roadmap to 2050. 2019, International Renewable Energy Agency (IRENA): Abu Dhabi.

23. European Union. European Green Deal. 2019 12.06.2020]; Available from: https://ec.europa.eu/info/strategy/priorities-2019-2024/european-green-deal en. 
This is a peer-reviewed, accepted author manuscript of the following research article: BraunholtzSpeight, T., McLachlan, C., Mander, S., Hannon, M., Hardy, J., Cairns, I., Sharmina, M., \& Manderson, E. (Accepted/In press). The long term future for community energy in Great Britain: a co-created vision of a thriving sector and steps towards realising it. Energy Research and Social Science.

24. UK Government, UK becomes first major economy to pass net zero emissions law. 2019, UK Government: London.

25. Henry, M.S., M.D. Bazilian, and C. Markuson, Just transitions: Histories and futures in a postCOVID world. Energy Research and Social Science, 2020.68.

26. Hall, S. and K. Roelich, Local Electricity Supply: Opportunities, archetypes and outcomes, in Realising Transition Pathways. 2015, University of Leeds: Leeds.

27. Brown, D., S. Hall, and M. Davis, Prosumers in the post subsidy era: an exploration of new prosumer business models in the UK. Energy Policy, 2019. 135.

28. Capener, P., Community Renewable Electricity Generation: Potential Sector Growth to 2020. 2014, Department for Energy and Climate Change: London.

29. Park, J.J., Community Energy Scenarios, in Grassroots Innovations Research Briefings. 2011, University of Sussex

University of East Anglia: Brighton and Norwich.

30. Edgar, J., J. Ahern, and M. Williams, The future of community energy. 2020, WPI Economics: London.

31. 10:10, Community energy: the way forward. 2016, 10:10: London.

32. Regen, Power to Participate: a specification for community energy to participate in a flexible energy system. 2019, Regen: Exeter.

33. Rostron, A., Assessing the viability of 'post-FiT' community energy business models in the UK. 2019, Imperial College: London.

34. Foxon, T., Transition pathways for a UK low carbon electricity future. Energy Policy, 2013. 52: p. 10-24.

35. Realising Transition Pathways Engine Room, Distributing Power: a transition to a civic energy future. 2015, Realising Transition Pathways Research Consortium: Bath.

36. Judson, E., et al., The centre cannot (always) hold: Examining pathways towards energy system de-centralisation. Renewable and Sustainable Energy Reviews, 2020. 118.

37. Sovacool, B.K., J. Axsen, and S. Sorrell, Promoting novelty, rigor, and style in energy social science: Towards codes of practice for appropriate methods and research design. Energy Research and Social Science, 2018. 45: p. 12-42.

38. Eames, M., et al., City futures: exploring urban retrofit and sustainable transitions. Building Research \& Information, 2013. 41(5): p. 504-516.

39. Gailing, L. and M. Naumann, Using focus groups to study energy transitions: Researching or producing new social realities? Energy Research and Social Science, 2018. 45: p. 355-362.

40. Quist, J. and P. Vergragt, Past and future of backcasting: The shift to stakeholder participation and a proposal for a methodological framework. Futures, 2006. 38: p. 10271045.

41. Vergragt, P. and J. Quist, Backcasting for sustainability: Introduction to the special issue. Technological Forecasting and Social Change, 2011. 78: p. 747-755.

42. Wangel, J., Change by whom? Four ways of adding actors and governance in backcasting studies. Futures, 2011. 43: p. 880-889.

43. Robinson, J.B., Energy backcasting: A proposed method of policy analysis. Energy Policy, 1982. 10(4): p. 337-344.

44. Hughes, N. and N. Strachan, Methodological review of UK and international low carbon scenarios. Energy Policy, 2010. 38: p. 6056-6065.

45. Massa, L., C. Tucci, and A. Afuah, A critical assessment of business model research. Academy of Management Annals, 2017. 11(1): p. 73-104.

46. Osterwalder, A. and Y. Pigneur, Business Model Generation: a Handbook for Visionaries, Game Changers, and Challengers. 2010, Hoboken, New Jersey: John Wiley and Sons. 
This is a peer-reviewed, accepted author manuscript of the following research article: BraunholtzSpeight, T., McLachlan, C., Mander, S., Hannon, M., Hardy, J., Cairns, I., Sharmina, M., \& Manderson, E. (Accepted/In press). The long term future for community energy in Great Britain: a co-created vision of a thriving sector and steps towards realising it. Energy Research and Social Science.

47. Joyce, A. and R.L. Paquin, The triple layered business model canvas: A tool to design more sustainable business models. Journal of Cleaner Production, 2016. 135: p. 1474-1486.

48. Braunholtz-Speight, T., et al., Business models and financial characteristics of community energy in the UK. Nature Energy, 2020. 5: p. 169-177.

49. Hall, S., Foxon, T. J., and Bolton, R., Financing the civic energy sector: How financial institutions affect ownership models in Germany and the United Kingdom. Energy Research and Social Science, 2016. 12: p. 5-15.

50. Ofgem, State of the energy market. 2019, Ofgem: London.

51. Committee on Climate Change, UK housing: fit for the future? 2019, Committee on Climate Change: London.

52. Morrison, K. and D. Moyes, Off-gas consumers: updated information on households without mains gas heating. 2018, Citizens Advice Scotland: Edinburgh.

53. Walker, G. and N. Cass, Carbon reduction, 'the public' and renewable energy: engaging with socio-technical configurations. Area, 2007. 39(4): p. 458-469.

54. Department for Energy and Climate Change, Community Energy Finance Roundtable: final report and recommendations. 2014, Department for Energy and Climate Change: London.

55. Nolden, C., Governing community energy - Feed-in tariffs and the development of community wind energy schemes in the United Kingdom and Germany. Energy Policy, 2013. 63: p. 543552.

56. Smith, A., et al., Making the most of community energies: three perspectives on grassroots innovation. Environment and Planning A, 2016. 48(2): p. 407-432.

57. Community Energy England, What is community energy and why does it matter? . 2014, Community Energy England: Sheffield.

58. Einarsson, T., Membership and Organisational Governance, in Department of Management and Organisation. 2012, Stockholm School of Economics: Stockholm. p. 246.

59. Seyfang, J., J.J. Park, and A. Smith, A thousand flowers blooming? An examination of community energy in the UK. Energy Policy, 2013. 61: p. 977-989.

60. Ofgem, Decarbonisation Programme Action Plan. 2020, Ofgem: London.

61. Ofgem, Flexibility Platforms in electricity markets, in Future Insights. 2019, Ofgem: London.

62. Community Energy England. Social Impact Tool. 2019; Available from: https://communityenergyengland.org/pages/social-impact-tool.

63. O'Leary, A. and G. Speciale, Monitoring and Evaluating Community Energy: Reviewing existing tools and outlining a pilot standardised tool. 2017, Leapfrog: London.

64. Cairns, I., et al., Edinburgh Community Solar Cooperative, in Financing Community Energy Case Studies. 2020, UKERC: London.

65. van Veelen, B., Making Sense of the Scottish Community Energy Sector - An Organising Typology. Scottish Geographical Journal, 2017. 133(1): p. 1-20.

66. Hielscher, S., Isle of Gigha Heritage Trust: An Innovation History, in Community Innovations for Sustainable Energy. 2013, University of Sussex: Brighton.

67. Haggett, C., et al., Community Energy in Scotland: the Social Factors for Success. 2013, University of Edinburgh: Edinburgh.

68. Goedkoop, F. and P. Devine-Wright, Partnership or placation? The role of trust and justice in the shared ownership of renewable energy projects. Energy Research and Social Science, 2016. 17: p. 135-146.

69. Walker, G., The role for 'community' in carbon governance. WIRES Climate Change, 2011. 2(5).

70. Committee on Climate Change, Net Zero: The UK's contribution to stopping global warming. 2019, Committee on Climate Change: London.

71. Forman, A., Energy justice at the end of the wire: Enacting community energy and equity in Wales. Energy Policy, 2017. 107: p. 649-657. 
This is a peer-reviewed, accepted author manuscript of the following research article: BraunholtzSpeight, T., McLachlan, C., Mander, S., Hannon, M., Hardy, J., Cairns, I., Sharmina, M., \& Manderson, E. (Accepted/In press). The long term future for community energy in Great Britain: a co-created vision of a thriving sector and steps towards realising it. Energy Research and Social Science.

72. Thombs, R.P., When democracy meets energy transitions: A typology of social power and energy system scale. Energy Research and Social Science, 2019. 52: p. 159-168.

73. Scottish Government, Local Energy Policy Statement. 2021, Scottish Government.: Edinburgh.

74. Government of Wales, Local ownership of energy generation in Wales - benefitting Wales today and for future generations, in Policy Statement. 2020, Government of Wales: Cardiff.

75. Community Energy England, Community Energy 2030 Vision. 2020, Community Energy England: Sheffield.

76. Wegner, M.-S., et al., Valuing energy futures; a comparative analysis of value pools across UK energy system scenarios. Applied Energy, 2017. 206: p. 815-828.

77. Berka, A. and E. Creamer, Taking stock of the local impacts of community owned renewable energy: A review and research agenda. Renewable and Sustainable Energy Reviews, 2018. 82: p. 3400-3419.

78. Gorrono-Albizu, L., K. Sperling, and S. Djorup, The past, present and uncertain future of community energy in Denmark: Critically reviewing and conceptualising citizen ownership. Energy Research and Social Science, 2019. 57.

79. Bauwens, T., Analyzing the determinants of the size of investments by community renewable energy members: Findings and policy implications from Flanders. Energy Policy, 2019. 129: $p$. 841-852.

80. Yildiz, O., Financing renewable energy infrastructures via financial citizen participation - The case of Germany. Renewable Energy, 2014. 68: p. 677-685. 